Il arrive souvent en temps d'épidémie, qu'on observe à la suite de la variole des laryngites diphthériques, qui présentent un caractère de malignité tout particulière. Laryngite morbilleuse. I a forme érethémateuse peut passer à la forme diphthéritique après une période de calme de quelques jours comme le prouvent deux observations de Coigne."

In Ziemssen's Cyclopædia, under Typhoid (i., page 165), it is stated: "Under some circumstances diffuse diphtheritic and croupous processes may extend into the larynx, and there produce deeper ulcerations and disturbances. The mucous membrane of the trachea is, however, rarely invaded."

Von Ziemssen says laryngeal catarrh is a frequent complication of typhus and typhoid fevers. In the latter it is not uncommonly followed by more or less deep ulcerations, and by perichondritis with laryngeal œdema. He does not speak of membranes.

Steiner speaks of secondary croup in measles, scarlatina, small-pox, whooping-cough, epithelioma laryngis, typhoid fever, pneumonia, and cholera, but he gives no cases.

Sestier just mentions three cases of pseudo-membranous laryngitis in typhoid. ${ }^{1}$

Türck in his rich collection of clinical cases has recorded one similar to this. Under the heading Secondary Croup, he says: 'This frequently occurs in the course, or among the sequelæ, of exanthematic processes of typhus, of cholera, of typhoid, of pyæmia, and in fact often combined with other exudative diseases, for instance, pneumonia, pleuritis, pericarditis, meningitis. In secondary croup the membranes are frequently thinner than in primary, so that they often only appear as a membranous coating (Anflug) although thicker, more solid membranes do occur. 'Then follow clinical cases, among them one of croup in typhoid, as follows :-

"A baker's wife, apparently about thirty years old, was, according to the report of her physician, between the third and fourth week of an attack of typhus. Already in the course of the illness she had complained frequently of choking (Würgen) and collection of tenacious mucus in the fauces. These difficulties had increased for the last two or three days, during which the pulse rose simultaneously to 108. At the examination held by me on January 29, 1862, I found on the posterior and lateral walls of the pharynx, especially on the right, a white, thick, consistent, adherent, croup membrave, which extended also to the posterior surface of the soft palate, and so far forward that it bordered the edges of the arches of the palate and the uvula. The whole free border of the epiglottis and the right ary-epiglottic fold, in part, as well as the mucous membrane covering the right $W$ risbergian and arytenoid cartilages, was covered with a similar membrane. The cords were normal. I have no information concerning the further course of the malady."

Türck apparently has not found this complication of typhoid so fatal as Griesinger would imply, for he says: "Larynx croup occurs both in exanthematic and in non-exanthematic typhus, in an early and in a late stadium, but it is almost always of inferior importance" (untergeordneter Bedeutung).

Mandl, regretting what he considers a useless division of the Germans of croup and diphtheria, according to the local symptoms, and declaring that we will not put pathology in tow of a globule, whose fantastic

1 Traité de l'Angine Edémateuse. Paris, 1852. voyages through meshes and pores defy the rich imagination of the poet, declares that " croup and diphtheria constitute a single great family, and croup is only diphtheria localized in the larynx ; nevertheless pseudomembranous affections of the larynx which are unconnected with diphtheria are also called croup. These are pseudo-membranous laryngitides which have neither the course, nor the reaction, nor the contagious specificity of diphtheria, and which cannot be considered as a stage of diphtheria not fully developed." Then he quotes Rokitansky and the Germans as giving the name of secondary croup to these pseudo-membranous exudations in measles, scarlatina, typhoid, etc., etc., and says that their diphtheritic character is not yet proved.

He goes on to say, "The membranes are generally thinner than in diphtheria; they may occupy only the larynx, or this and its vicinity, taking their rise from some point of the pharyngo-laryngeal passages. They sometimes determine an acute aud fatal odema. I have noticed analogous exudations, grayish white, isolated, circumscribed, in syphilitic and tuberculous laryngitis and, as has been stated, in some cases of chronic parenchymatous laryngitis."

Furtler quotations would be tedious. The complication of typhoid fever by secondary croup, although rare, is well recognized, but not in the works in the hands of most general practitioners.

Published cases are hard to find, anatomical specimens must be very rare. I have therefore brought this case and specimen before you, hoping that it may not only be interesting in itself, but as a means of eliciting an expression of opinion concerning the real nature of such cases, which are connected directly with the question of the relation between, or identity of, croup and diphtheria.

\section{THE THERAPEUTICS OF VENESECTION.2}

BY WM. A. DUNN, M. D.

IT is difficult to recall a subject which so strikingly suggests the revolution which has taken place in therapeutics within the past quarter of a century, or which convinces an observer so earnestly that there is not that stability in the rules goveruing the application of medical meaus for ends which the practitioner would desire, or the symptoms of an illness demand. A practice which dates from the days of the faiher of medicine, and was so universally practiced in the ages following, winning for its adherents authorities like Galen, Sydeuham, and Hunter, and in our day, Fordyce Barker, Graefe, Brown-Séquard, and Bowditch, could not have been so devoid of merit as the apathy and denunciation of these later times would seem to warrant. And yet if we reflect on the history of venesection we shall find that its course has not been much dissimilar from that of mercury, the alkaline treatment, and the various methods which have existed in our day, and which have won enthusiasts until time has tested their claims to merits, and placed them in their proper sphere. In their turn scoffers may deride the unlimited confidence we give carbolic acid, iodoform, and the salicylates, the abuse of which would operate as many evils as the abuse of venesection. Modern physiology and pathology have removed the ignorance which permitted the

2 Read at the meeting of the Section for Clinical Medicine and Pathology of the Suffolk District Medical Society, April 8, 1882. 
many gross errors which prevailed in the days of wholesale venesection, a practice which was alike the function of the barber and leecher as well as the resource of the court physician. As we read of the many cases reported in which venesection was performed, apparently with the only aim in view to exhaust the patient as speedily and effectually as possible, we cannot help deploring the abuse of venesection, and wondering why the patient of a former generation was so difficult to be killed. The refinement of modern therapeutics as well as the barbaric precepts of the ancient bleeders have been the main factors which have brought venesection into disrepute. The advocates of blood-letting would seem to have cast odium upon their practices by the precepts which they taught. For instance, Dr. Elliotson, in speaking of enteritis, says: "The first thing one has to do is to bleed the patient well. You must set him upright as be can be, and bleed him from a large orifice without mercy." An authority no less distinguished than Robert Jackson, formerly surgeon-general of the British army, frequently removed four pounds at one time, which was considered a moderate bleeding. Six pounds have been taken on several occasions, and a hundred and twelve ounces at a single bleeding in some. This practice, so formidable in appearauce, implied no danger. He declares the practice is reasonable in theory, and is proved by experience to be founded on truth. Certainly the results reported by. Jackson were extraordinary, for he says that fuinting did not always occur, and the patient in most cases returned to his military duty within eight days in the full vigor of health. Galen is quoted as having bled largely during the plague, and he is the first to record the quantity taken. He says that he has taken from the patient in one bleeding six pounds of blood, which immediately extinguished the fever, nor was there any loss of strength in consequence. In these days of pilocarpine, aconitine, atropine, and the subcutaneous syringe, we can reflect on the therapeutics of only a few years ago. If we are to credit the wonderful reports of cases of recovery after extraordinary losses of blood, we are warranted in relieving the popular mind of the terrors which it entertains concerning hæmorrhages.

John Hunter is quoted as having seen several quarts of blood ejected from the stomach even by emaciated subjects, and improvement speedily followed the evacuation. Laucisi relates the case of a man of seventy who suddenly lost in a threatened attack of apoplexy eleven pounds of blood from his nose, and four more in fifteen days afterwards, without any visible failure of strength. Boerhaave and Haller have both reported remarkable hæmorrhages which have not seemed to have been followed by any evil result.

Nothwithstanding the many abuses to which venesection has been subjected, the fundamental principle presents claims for our attention and deserves application in special and well selected cases, and if we analyze the therapeutics of venesection we shall find sufficient cause for commendation and eager following.

There is no doubt that venesection was formerly used too indiscriminately and often employed too largely, but Dr. Flint says that with the natural tendency to pass from one extreme to the other it may be that the utility of blood-letting in certain cases at the present time is not sufficiently appreciated. The rules which governed the advocates of venesection in former times were in accordance with the lights which they possessed, and the methods which permitted the physi- cian of a former time to continue his venesection until the coagulation ceased or until complete syncope declared itself, are a commentary on their limited knowledge of physiology and pathology. We now know without doubt that by a venesection we do not really diminish the amount of blood in the circulation, but we devitalize the blood of its most important factors, by robbing it of much of its fibrin and red globules, which are not readily reproduced. In accordance with fixed laws of endosmosis the blood becomes thinner and decidedly anæmic by its absorption of the fluids from other parts of the body, and in this manner the vital functions are impaired. It will be likely to effect harm, therefore, whenever it is important to economize the powers of life, and it may contribute to a fatal result in diseases which involve danger to life by asthenia.

Flint says that blood-letting is never indicated by the fact that acute inflammation exists ; it is a measure directed not to the disease per se, but to circuinstances associated with the disease. It is admissible, if with the development of inflammation there exist high symptomatic fever, the pulse denoting augmented power of the heart's action, the patient being robust, and the disease not involving danger to life by asthenia. Venesection is admissible under the conditions just stated whenever the promptuess with which its effects are obtained renders it desirable to adopt it in preference to other measures producing the same effect with more or less delay. If we are to be consistent, we should be guided by the motto, Naturâ duce, of our Society, and we should receive many a suggestion from the natural operations continually presented to us in the natural course of a disease. Every one is familiar with the relief which comes to headache by an epistaxis - to the congested uterus by a menstrual flow, or to dyspnœa by a slight hæmoptysis. I have at present a patient who has received within a few hours immense relief to a severe bronchitis by the appearance of her menses, when the ordinary remedies seemed to have failed. It is a well known fact that the temperature declines to an appreciable extent after an epistaxis, which, in most cases, is disproportionate to the amount of blood lost. Wunderlich says that after a moderate venesection the temperature rises a few tenths and gradually returns to the normal after a day or two, and may even at a later period sink below the normal.

Frese ${ }^{1}$ says immediately after a moderate bleeding a fall of temperature of about $1^{\circ} \mathrm{C}$. or $1.8 \mathrm{~F}$. ensued, but after a few hours the temperature began to rise, and generally exceeded the temperature before the bleeding. Wunderlich says that general blood-letting in suitable cases of disease and in a less degree local abstraction of blood have a similar effect, and it not seldom happens that the temperature, which just before was considerably elevated, becomes normal, or very nearly so, soon after. In most cases the temperature soon rises again to its previous height or even exceeds it. The temperature will remain reduced just in proportion to the actual improvement which has taken place in the patient's condition, at or after the bleeding, and the most decided influence on the course of the fever is brought about by a sufficiently copious blood-letting or a spontaneous hæmorrhage (as in epistaxis or in menstruation). Granting that there are special indications for blood-letting, it is important to know when and how we are to avail ourselves of this agent and when to cease. Generally, a condition

\footnotetext{
1 Virchow's Archiv.
} 
of plethora with inflammatory symptoms would indicate it, especially if there is a full, bounding pulse. In limiting the amount of blood to be drawn we should not be guided by the condition of the pulse alone so much as by the improvement in the general condition of the patient. We are justified in supposing that many of the reported cases are grossly exaggerated, but it is an undoubted fact that venesection was much abused before the methods of the cold-water pack and the febrifuge effects of quinine were thoroughly appreciated. I have had an opportunity of testing the efficacy of venesection under the following circumstances.

Several months ago a patient whom I had never treated before presented himself at my office complaining of a headache, which was bilateral and at times very intense. His digestion was in good condition; he was not losing an appreciable amount of strength, and he was able to attend to his work, but with less vigor than formerly. As he was a great smoker and a hard worker $I$ attributed his symptoms to an excessive use of tobacco and hard work. I advised him to rest, to moderate his use of tobacco, and to take tonics. There was no vomiting nor œdema, nor were there any symptoms which would attract my attention to his kidneys if $I$ might except a slight dimness of vision, which, considered in connection with bis headache and slight debility, caused me to request him to allow me to examine the urine, which he neglected to do. His age was forty-two. As he was an ordinary office patient he passed from my attention until late one evening I was called to attend him by a messenger who told me that the patient was suddeuly seized with convulsions. I learned that the patient had continued to complain of his head and of amaurosis, but apart from those symptoms he had been apparently well until a few days before the convulsions appeared, and in fact he had continued working, although he was growing more feeble, and other symptoms which evidently indicated nephritis had supervened, such as cedema of the feet, hands, and face, with vomitivg, and pain in the lumbar region, together with a diminution in the amount of urine passed. When I arrived at his house I found the patient in a profound coma, with convulsions. His pupils were dilated. His skin was dry and hot, and the frontal veins and face were moderately although not remarkably swollen. The œdema was slight. There was a full, bounding pulse, and the apex beat was abnormally labored, full, bounding, and slow. The temperature was $102^{\circ} \mathrm{F}$., and the small quantity of urine which I was able to obtain was quickly coagulated by heat during the necessary delay prior to the application of the measures for relief, and relief was demanded at once. There was no time for the application of diaphoretics, diuretics, nor other derivatives. Death was imminent, and I believe would have speedily followed had not immediate action been taken.

I remembered that when $I$ was a student in the office of Dr. H. I. Bowditch he had advocated venesection under proper conditions, and although I could not remember that $I$ had heard any direct teaching given on the subject, I determined to bleed in the present case, and to follow the advice given by Dr. B. W. Richardson, and quoted by Dr. Bowditch, who claimed for venesection a first place in the treatment of uræmic convulsions. I allowed ten ounces of blood to flow from the median cephalic vein, from which the blood came in a dark and steady stream. The relief which ap. peared after the venesection was not long delayed, and was most satisfactory. The convulsions ceased, the face assumed a more natural hue, the pulse lost its labored character, the breathing became easier, and consciousness after a short interval returned. He was then wrapped in hot and moist blankets, and was given an eighth of a grain of elaterium. Perspiration was excited, and he rested easily. Under diuretics and jaborandi and milk at first, and afterwards Basham's mixture, the patient made a slow and gradual recovery, with a single intermission on the fourth day, when it was necessary to remove five ounces of blood.

The urine at first contained abundant epithelial and granular casts; it was of low specific gravity, 1008 , and contained a large quantity of albumen. After three months the albumen and casts had wholly disappeared from the urine, the odema had disappeared, and, except a diminution of general vigor, the patient was really well.

I consider the case one of acute nephritis occasioned by exposure to cold in a patient considerably debilitated tated by hard work and general disregard of hygienic laws. Nephritis sometimes approaches so insidiously, and with symptoms so slightly emphasized, that a diagnosis is oftentimes difficult unless an examination of the urine is made. In this connection it may not be irrelevant to the subject to state that as obscure renal diseases are sometimes suspected by the single symptom of vomiting, to which Dr. Ellis attracted attention, so in like manner a headache, especially if bilateral, intense, and accompanied by amaurosis, may attract attention to a nephritis of which it may be at first the only symptom of dangerous conditions. The cry of venesection may be imagined to be, "Save me from my friends."

From the consideration of this subject we are justified in drawing the following conclusions:-

(1.) That although the errors of former days, without doubt, allowed a very great abuse of venesection, it has sufficient merit as a therapeutic agent to demand our earnest consideration.

(2.) If we are sincere in following the motto of our Society, Naturâ duce, we shall take the suggestions which nature gives and bleed in carefully selected cases.

(3.) 'That in febrile attacks a loss of blood will lower the temperature, and this decrease in temperature is known to be disproportionate to the amount of blood lost.

(4.) 'That by venesection we do not actually diminish the volume of blood, but we cause the blood to become more watery, the free passage of the blood through the pulmonary circuit seems to be promoted, and the functional labor which the lungs have to perform is diminished by the abstraction of a certain number of the more solid particles.

(5.) It is fallacious to depend upon the condition of the pulse alone as the criterion of the amount of blood to be removed, or the benefit which the patient derives by a venesection. After a venesection the pulse sometimes appears to indicate increased power of the heart's action. 'The artery seems to strike against the finger with more force than before the abstraction of blood. Formerly practitioners were misled by this effect upon the pulse, and blood-letting was employed as a means of increasing the power of the heart's action. The sensation which the finger receives is delusive, and is caused by the quickness of the movements of the artery.. 'This has been shown by the sphygmograph to depend on the diminished tension of the arteries following the abstraction of blood. It is to be borne in mind, says Flint, in estimating the power of the heart's ac- 
tion by the sensible characters of the pulse, that the sense of resistance which is felt and the amount of pressure required to impress the artery are the evidences of strength. I cannot do better than to make use of the statements quoted in Dr. Bowditch's monograph on venesection which he read at the annual meeting of the Massachusetts Medical Society, in 1871.

"Dr. Richardson says : "If blood-letting were in this day an unknown remedy, and were some man to discover it, we should receive that man as the greatest amongst us, and seud him to posterity as one of the lights of the age.' And again he says: "The confidence of the ancients in the practice of blood-letting, their fearlessness of any immediate danger from it, was, I believe, as well founded in truth, as the cowardice and assertion, without observation, of the present day is founded on error.' He sums up as follows : ' $I$ would recall that blood-letting as a point of scientific practice is still open to us in some stages (early stages) of typhoid fever, in cases where there is a sudden tension of blood, of which sunstroke is an example; in cases of chronic congestion of the brain; in cases of acute pain from (inflamed) serous membrane; in some cases of spasmodic pain (gall-stones, etc.); in others of sudden arrest of circulation from concussion ; in congestion of the right heart, and it may be in some cases of extreme hæmorrhage. Above all I claim for it a first place in the treatment of simple uræmic poisoning.'

"Dr. Sutton ${ }^{2}$ gives cases in which bleeding was resorted to to relieve distention of heart and passive congestion of the lungs. He ordered it, not to relieve inflammation, but to cure obstructions.

" Fordyce Barker, M. D. : ' ' I am gradually getting to bleed more frequently. My conviction that this resource in practice has been too much neglected by myself and others has been progressively growing for some years.' 'Dr. Barker would bleed to prevent abortion in some cases. ${ }^{4}$ So in renal congestions of the brain with coma, and when the skin is hot there is nothing so sure. He would bleed a woman in convulsions thirty ounces, and give elaterium also. 'We must not,' he also declares, ' avoid bleeding in some cases even if the patient is feeble. In puerperal mania, at least in some very rare cases, venesection is of the greatest benefit.

\section{REPORT ON GENERAL PHYSIOLOGY.}

BY CHARLES SEDGWICK MINOT, M. D.

Among recent investigations we select especially several important researches upon the nervous system and the function of respiration.

Professor Goltz, of Strassburg, has published a fourth paper $^{5}$ on the functions of the cerebrum, and has also gathered his memoirs on this subject into a volume that appears as a separate publication. ${ }^{6}$ The numer-

1 Address Introductory to the Ninety-fifth Session of the Medical Society of London, on Blood-letting as a Point of Scientific Interest, by B. W. Richardson, M. D., F. R. S., President. Practitioner, No. 5 , November, 1868.

2 Medical Times and Gazette, December 18, 1869

8 New York Medical Journal, January, 1871.

4 "In former days abortion, even that had gone so far as to cause bloody discharges from uterus, I have seen checked by venesection. H. I. BowDrTch."

5 Friederich Goltz. Ueber die Verrichtungen des Grosshirns. Vierte Abhandlung. (Unter Mitwirkung von Dr. J. von Mering und Dr. R. Ewald.) Pflüger's Areh., xxvi. (1881) 1-49, Taf. i.-iii.

6 Friederich Goltz. Ueber die Verrichtungen des Grosshirns. Gesammelte Abhandlungen. Bonn. 1881. Pages 173. ous experiments, which have been made during the last few years, on the localization of the functions in the brain by attempts to find specific centres in the cortex cerebri, seem to have accomplished little more than to show that electrical irritation of a limited area produces in each case a definite result, but it has not been proven that the constancy of the result extends always beyond one individual. On the contrary, one observer recognizes in a certain spot the centre for one action which another places elsewhere, while a third assigns to the spot another function. Until, therefore, the observers are agreed as to the functions and positions of the centres, the theory of circumscribed centres in the cortex cannot be definitely adopted.

Goltz's experiments put an even greater difficulty in the way of this theory. He has removed large portions of the brain in dogs by various methods, and has succeeded in keeping the animals alive for long periods after the operations were performed on them. He has found that the operation causes certain temporary disturbances, but that the permanent effect is a general diminution of the mental power, roughly proportional to the amount of brain substances removed. The extirpation of a circumscribed area never produces any definite, limited, permanent disturbance.

In his earlier experiments a canula was pushed into the substance of the brain, and a stream of water forced through it, thus washing off the nervous substance, but injuring the blood-vessels so little that there was no great bleeding. In the later experiments he used a bunch of fine needles soldered on to a plate (fourteen to a square centimetre), which he plunged into the part to be destroyed. Finally he used a White's dental engine to cut off pieces of the cortex. He divides the cerebrum into four quadrants by considering each half to be separated into an anterior and a posterior quadrant. The first dog, whose condition Goltz describes, underwent four operations at considerable intervals; each time nearly the whole of a quadrant was removed, yet the animal lived perfectly healthy for a year and eleven days after the last operation. It was then intentionally killed, and the brain showed not only the loss of substance actually removed, but had also undergone a very considerable atrophy. Now, this dog was extremely dull, stupid, and indifferent (blödsinnig), but still accomplished his cerebral functions, although imperfectly. He could see well enough to get assistance from his eyes in avoiding objects. When his eyelids were closed by sticking plaster he tried very awkwardly to remove the plaster, and when he moved bumped constantly against objects which he avoided with open eyes. He paid no apparent attention to anything around. Gave no heed to strange cats or dogs. He was not deaf, because he could be aroused from sleep by loud calls. He preserved his other senses likewise with greatly diminished acuteness. He was unable to manage his body in a way well adapted to the end in his view. Many ingenious and often amusing devices were employed to test his mental capacity. He might be characterized most briefly as a dull idiot, never making any expression of pleasure, although he could be put into a violent rage. Such were the permanent results of the injuries; the temporary effects were not less remarkable. After the first operation (removal of the left anterior quadrant) the characteristic disturbances appeared. When the dog attempted to walk the right legs yielded, and he 